\title{
Migration speed and scheduling of annual events by migrating birds in relation to climate change
}

\author{
A. Hedenström ${ }^{1, *}$, Z. Barta ${ }^{2,3,4}$, B. Helm ${ }^{5}$, A. I. Houston ${ }^{4}$, J. M. McNamara ${ }^{3}$, N. Jonzén ${ }^{1}$ \\ ${ }^{1}$ Department of Theoretical Ecology, Lund University, Ecology Building, 22362 Lund, Sweden \\ ${ }^{2}$ Behavioural Ecology Research Group, Department of Evolutionary Zoology, University of Debrecen, Egytem tér 1, \\ 4032 Debrecen, Hungary \\ ${ }^{3}$ Department of Mathematics, University of Bristol, University Walk, Bristol BS8 1TW, UK \\ ${ }^{4}$ School of Biological Sciences, University of Bristol, Woodland Road, Bristol BS8 1UG, UK \\ ${ }^{5}$ Max Planck Institute for Ornithology, Andechs, Germany
}

\begin{abstract}
Empirical evidence for changed timing of migration in birds is emerging from both American and Euro-African migration systems. These changes are usually interpreted as a consequence of changes in climate. Responses in timing of migration and breeding may differ among species, and the adaptive significance is not well understood. There is a lack of theoretical understanding about time-shifts in life-history events due to climatic changes. In the present paper, we use 2 separate modelling approaches to investigate the effects of climate change on migration. We first use a simple model of flight speed and foraging to explore which factors may influence migration speed and stopover itinerary. Our second approach derives predictions based on an annual routine model, where behavioural strategies regarding timing of migration, breeding, moult and number of breeding attempts are modelled in an environment comprising 4 locations (breeding and wintering sites and 2 stopover sites). This approach takes account of interrelationships between behaviours and seasons as a step towards realistic modelling of migratory connectivity. Departure from the wintering site is advanced in relation to the advancement of spring if the moult is in summer, but not so for species with a winter moult, while arrival at the breeding site is advanced for both moult scenarios. Timing of breeding and number of successful broods were also affected by spring advancement, while start of moult is relatively unaffected by climate change. These optimal solutions under the modelled set of parameters are discussed with respect to current knowledge of the mechanisms underlying seasonal timing in birds.
\end{abstract}

KEY WORDS: Annual routines $\cdot$ Climate change $\cdot$ Phenology $\cdot$ Timing of breeding $\cdot$ Bird migration

\section{INTRODUCTION}

There is mounting evidence that increased amounts of anthropogenic gases in the atmosphere lead to measurable changes in climate and temperature (IPCC 2001). Observations of phenological shifts in the timing of breeding and migration in birds have generally been attributed to climate change (Crick et al. 1997, Dunn 2004, Lehikoinen et al. 2004). Analyses of bird observatory data have shown advancement in the timing of spring migration (Hüppop \& Hüppop 2003, Lehikoinen et al. 2004, Stervander et al. 2005, Jonzén et al. 2006, Tøttrup et al. 2006), as well as advancement in the timing of autumn migration by long-range migrants and postponement in short-range migrants (Jenni \& Kéry 2003). Yet changes in phenology were not homogeneous between species and populations, nor between different seasonal behaviours within a given species. For instance, in pied flycatchers Ficedula hypoleuca studied in the Netherlands, observed patterns included the advancement of laying date, but only a weak shift in arrival date (Both \& Visser 2001). 
Recent research has addressed possible reasons for the observed diversity of changes in phenology, with particular attention to the timing of spring migration (Webster et al. 2002, Van Noordwijk 2003, Both et al. 2005, 2006, Jonzén et al. 2006, 2007, Gienapp et al. 2008). This debate has brought up important aspects contributing to changes in phenology. Based on evidence for genetic timing programs, fast microevolutionary change in migration behaviour has been invoked and documented in individual cases (Gwinner 1996, Pulido \& Berthold 2003, Bearhop et al. 2005). Further, changed migration schedules may be based on phenotypic plasticity, for instance via programmed mechanisms (e.g. photoperiodic response; Gwinner 1996, Gienapp et al. 2008) or behavioural decision rules in direct response to temperature and other environmental factors (Cochran \& Wikelski 2005). Last, changed schedules could be partly explained by carryover effects between seasonal behaviours of individuals, due to connectivity between the different localities visited by migratory birds (see Section 2.2). Independent of the particular mechanisms involved, the advancement of spring migration could be due to: (1) an earlier onset of spring migration from the wintering area; (2) changed spatial patterns, for instance, shorter migration routes; or (3) an unchanged onset of migration, but an increased speed of migration. For the Palaearctic-African migration system the relative role of the 3 scenarios for advanced spring migration is under debate (Jonzén et al. 2006, Gienapp et al. 2008, this issue). In eastern North America, earlier migration seems to be mainly due to increased migration speed (Marra et al. 2005). Theoretically, if temperature increases at spring stopover sites, this may increase the migration speed (Ahola et al. 2004, Both et al. 2005), which may lead to earlier arrival at the breeding area. However, if climate change affects locations along the migration route and breeding site differently, the outcome may be a shift in migration timing, but not in timing of breeding (Ahola et al. 2004).

It is quite clear that shifts in the timing of different life-history events among migratory birds do occur. Most studies report the change in one trait, such as timing of migration or breeding. However, changing one trait is likely to have knock-on effects on other activities (e.g. Webster et al. 2002, Norris et al. $2004 a, b)$. How such relationships may be interrelated is still rather unexplored. The main annual processes in a migratory bird include breeding, migration and moult, and given a limited amount of time, shifting one of these events should affect the others (Hedenström 2006). To address this question, we adopt two independent modelling approaches. The first approach uses equations from migration theory (Alerstam \& Hedenström 1998) to explore the effect of climate change on the overall speed of migration. This approach has the advantage of simplicity, but achieves this by considering a migratory journey in isolation from the whole annual routine. Our second approach is based on an annual routine model (Barta et al. 2006, 2008), in which the timing of events around the year is interrelated. The model finds the optimal annual routine, i.e. the strategy of breeding, migration and moult throughout the annual cycle that maximizes reproductive success. We use the optimal strategy to investigate the effect of climate change on the scheduling of events in the annual cycle. For our model, the particular mechanisms by which optimal strategies may be implemented are not important. A change of strategy in response to climate change may be an evolutionary response, or potentially a change as a result of phenotypic plasticity. Based on knowledge of particular mechanisms, genetic architecture, or ecological needs, we may make predictions whether a given species will implement optimal strategies, or the ways in which its response to climate change may differ from predictions. This paper is thus an attempt at modelling and predicting effects of climate change on life-history events in migratory birds, which hopefully could be tested and further refined using data available from bird ringing stations and long-term studies of breeding ecology.

\section{THEORY}

\subsection{Migration speed}

In this section we explore how migration speed in spring and autumn is likely to be affected by changed climate as a result of global warming. We assume that increased temperature leads to increased food abundance, as considered likely during spring migration, although other scenarios are also possible. We model effects on 2 types of migration: one progresses along continuous environments, as exemplified by generalist passerines that use diverse habitats in which to stop and refuel. The other type progresses along discrete environments, e.g. species requiring particular and patchily distributed stop-over habitats, such as geese, shorebirds and specialized passerines.

\subsubsection{Speed of migration in continuous environments}

Optimal migration theory analyses migration strategies based on the performance with respect to one or a combination of alternative currencies, such as mortality risk, energy cost of, or time taken for, migration (Alerstam \& Hedenström 1998, Houston 1998). The 
currency most relevant to timing schedules of migration in relation to climate change is the overall speed of migration, which, when fast, leads to a short duration of migration (and hence early arrival at the breeding or over-wintering site). If natural selection favours behaviours that lead to an overall fast migration speed and therefore a short duration of the migration, we refer to this as time-selected migration. The overall speed of migration depends on a few properties only: flight speed $(U)$, gross rate of energy accumulation at stopovers $\left(E_{0}\right)$, the rate of energy consumption when at stopovers $\left(C_{0}\right)$ and the rate of energy expenditure during flight $(P)$. Migration speed can be written as (see Hedenström \& Alerstam 1995):

$$
S_{\text {migr }}=\frac{U\left(E_{0}-C_{0}\right)}{\left(E_{0}-C_{0}\right)+P}
$$

We will focus the discussion on birds migrating by flapping flight, where $P$ is a function of flight speed through the air (Fig. 1). This relationship is a U-shaped function as derived from the basis of flight mechanical theory (Pennycuick 1975, 1989) and confirmed by experiments (Tobalske et al. 2003, Askew \& Ellerby 2007). Given this description of migration speed, we can address the potential effects of climate change by considering the factors on the right-hand side of Eq. (1). Thus, we may infer how possible effects due to climate change may affect the speed (and hence phenology) of bird migration.

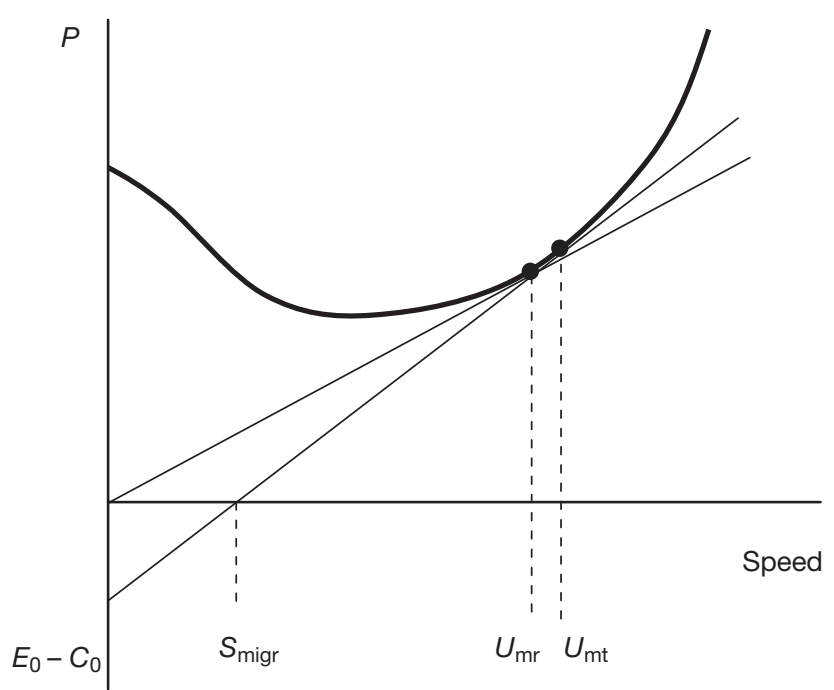

Fig. 1. The relationship between the power required to fly and forward airspeed (often termed 'power curve') typical of avian flight. The net rate of energy accumulation, $E_{0}-C_{0}$, is denoted on the extended $y$-axis. $U_{\mathrm{mr}}$ is the maximum range speed obtained by constructing a tangent from the origin to the power curve, $U_{\mathrm{mt}}$ is the speed associated with time-selected migration and obtained by constructing a tangent from a point along the extended $y$-axis representing $E_{0}-C_{0}, S_{\text {migr }}$ is the resulting migration speed given by the intersection of the line between $E_{0}-C_{0}$ and $U_{\mathrm{mt}}$ on the power curve and the $x$-axis
First, flight speed, $U$, should be selected so as to maximize the overall migration speed. Typically, flight speed is approximately 12 times the overall migration speed. There is an optimal flight speed associated with time-minimizing migration, $U_{\mathrm{mt}}$, which is slightly higher than the maximum range speed, $U_{\mathrm{mr}}$, which is associated with the minimum energy cost of migration (Fig. 1; Alerstam 1991, Hedenström \& Alerstam 1995). The time-selected optimal flight speed depends on the net rate of energy accumulation $\left(E_{0}-C_{0}\right)$ and increases when this quantity increases. The fine tuning of flight speed has relatively little effect on the overall migration speed, $S_{\text {migr, }}$ but if the net energy accumulation rate is increasing due to climate change, the prediction is that with everything else equal the flight speed should increase (see Appendix 1).

If the net rate of energy accumulation, $E_{0}-C_{0}$, increases, the overall migration speed, $S_{\text {migr, }}$ will increase (Hedenström \& Alerstam 1998). This is easily seen in Fig. 1, where $S_{\text {migr }}$ is the intersection of a tangent starting from a point on the extended ordinate representing the net energy accumulation rate, and the $x$-axis representing speed. Hence, an increased absolute $E_{0}-C_{0}$ will move the origin of the tangent downward, and therefore the intersection point with the $x$ (speed)-axis will slide to the right. An increase of the net energy accumulation rate can be achieved from an increase of the energy intake rate $E_{0}$ and a decrease in the energy $\operatorname{cost} C_{0}$, or a combination of these 2 factors. Hypothetically, a decrease in the costs could be due to reduced thermoregulation costs with increasing temperature (but below the critical point causing heat stress), or to reduced locomotion costs if food distribution, and hence search strategy, change as a response to climate change. Increased food abundance is likely to increase the ingestion rate, and hence the net energy accumulation rate will increase. However, birds are considered to have a metabolic constraint so that, above a certain level of energy intake, the assimilation capacity is maximum (Kirkwood 1983, Lindström 1991). This ceiling defines a physiological maximum of the intake rate and of converting food into adipose tissue, which also defines the maximum migration speed (Hedenström \& Alerstam 1998). Hence, if food abundance increases due to climate change beyond the limit of the metabolic ceiling, we may expect an increased migration speed up to this point, but with further increased food abundance the birds will not be able to respond because of the metabolic constraint. There are birds already experiencing food abundances at stopovers which are close to the metabolic ceiling (Hedenström \& Alerstam 1998). Hence, based on food availability alone, migration speed could not be increased further for these species. Finally, the power required to fly, $P$, is determined mainly by the physical properties of air 
and morphology. For an ideal bird (sensu Pennycuick 1975), $P \propto \rho^{-1 / 2}$, where $\rho$ is air density. If air density increases due to changed composition of the atmosphere, then power required to fly will decrease, and hence the overall migration speed will increase. The effect for this may initially be small, but there have been eras in the history of the earth when air density was significantly different from that at present, and this may have had profound consequences for organisms (Graham et al. 1995).

As detailed in Appendix 1, the effect of a change in fuelling rate $\left(E_{0}-C_{0}\right)$ on $S_{\text {migr }}$ depends on the existing value of $E_{0}-C_{0}$. When $E_{0}-C_{0}$ is low, so that most migration time is spent on refuelling, a proportionate increase in $E_{0}-C_{0}$ is accompanied by essentially the same proportionate increase in $S_{\text {migr }}$. In contrast, when $E_{0}-C_{0}$ is already high, so that most time is spent flying, an increase in $E_{0}-C_{0}$ has little effect on $S_{\text {migr }}$.

\subsubsection{Speed of migration in discrete environments}

In this model, the stopovers occur as discrete points along a fixed migration route and the local energy accumulation rates determine which sites should be used and for how long. The migration systems represented by certain arctic breeding shorebirds and wildfowl are likely to be represented by this model. The currency is the instantaneous migration speed, written as:

$$
S_{\text {inst }}=\frac{C}{2} k\left(1-\frac{Y}{C}\right)^{3}
$$

where $k$ is the daily rate of fuel accumulation expressed as a proportion of the lean mass, $Y$ is the potential flight range, and $C$ is a constant including physical and morphological properties of the atmosphere and bird (Alerstam \& Hedenström 1998). Eq. (2) is obtained by taking the time derivative of a function describing the potential flight range. $S$ represents the marginal rate of gain in flight range for a bird depositing fuel at a daily rate $k . S_{\text {inst }}$ declines with increasing flight range. The decision whether to stay or depart depends on the distance(s) to subsequent stopover(s) and the expected fuelling rates they provide. The optimal strategy is the combination of stopover sites and fuelling policy that produces the fastest arrival to the destination.

The inclusion of a certain stopover site depends on the rate of fuel accumulation, $k$, that the bird can achieve there. With discrete stopover sites, their specific $k_{i}$ will determine whether a site should be used or skipped (Weber et al. 1994, Alerstam \& Hedenström 1998). Consider the hypothetical arrangement shown in Fig. 2. Here, the bird will start from Site 1 (which could be the wintering site). It should accumulate fuel

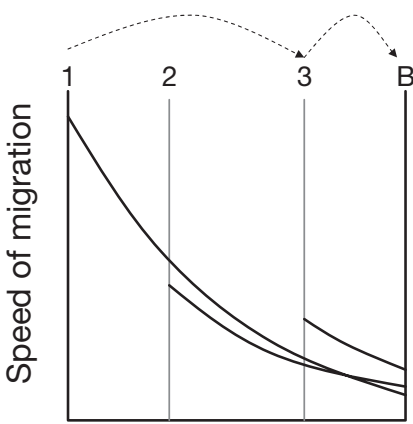

Flight range

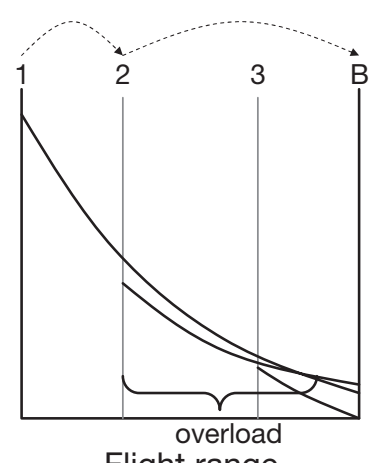

Flight range
Fig. 2. Hypothetical optimal choices of stopover sites and fuel loads for birds maximizing the speed of migration with a discrete set of stopover sites. In the left panel, birds accumulate fuel to reach Site 3, where they fuel to reach the breeding area (B). They thereby bypass Site 2 in favour of Site 3, although Site 2 has a higher fuelling rate than Site 3. In the right panel, Site 2 does not provide a fast enough fuelling rate (assumed to be due to an effect of climate change). The birds now accumulate fuel at Site 1, but much more than needed to reach Stopover 2 (overload); they then fly to Site 2 and top up the fuel so they can reach the breeding site (B) in 1 flight. They thereby bypass Site 3, which was used earlier. The curves show the instantaneous rate of migration in relation to potential flight distance. Modification is based on Alerstam \& Hedenström (1998)

so that Site 3 will be reached, and then accumulate fuel there that will cover the remaining flight distance to the breeding site (Fig. 2, left panel). If there is climate change that modifies the utility of Site 3 , so that the fuelling rate is reduced (Fig. 2, right panel), then the best strategy for the bird will be to accumulate an overload at Site 1, then fly on to Site 2 where the fuel load will be topped up to allow a direct flight to the breeding site. In this case, Site 3 will not be used. The overall speed of migration will decrease in the illustrated example due to deterioration at Site 3 and migration with overload.

\subsection{Annual routines}

The optimal annual routine approach allows trading off behaviours against each other when maximizing a more general fitness measure, such as life-time reproductive success (as opposed to, e.g., overall migration speed, as used in simple optimization models). For instance, increased food availability will not necessarily result in an increased energy gain. The birds may use more plentiful food to reduce foraging intensity in order to reduce predation risk (and hence survival), which may lead to an unchanged migration speed. Another reason for using the optimal annual routine approach is that changed behaviour during one period may affect those of a subsequent period (knock-on 
effects), which will feed back into the overall optimal annual routine solution. Hence, this is a more general approach for studying the optimal scheduling of events in a periodic environment (Houston \& McNamara 1999, McNamara \& Houston 2008).

\subsubsection{The model}

Behavioural decisions are generally thought to be based on the current state of an animal, such as its location, time (with respect to diurnal or annual cycle), condition, breeding state, etc. Problems related to the organization of events in an annual cycle can be considered and derived using a class of models denoted annual routine models (McNamara et al. 1998, Houston \& McNamara 1999, McNamara \& Houston 2008). The technique employed to find the optimal strategy is known as dynamic programming (Houston et al. 1988, Clark \& Mangel 2000, Houston \& McNamara 1999). A detailed annual routine model based on stochastic dynamic programming aimed at studying migration and moult timing of birds in a seasonal environment was recently developed by Barta et al. (2008). This model includes 4 behavioural traits: (1) reproductive behaviour, (2) foraging intensity, (3) migration and (4) moult of primaries. The rationale for including foraging intensity in the model is that, because of predation risk, it should not be optimal to always forage with maximum intensity, while, on the other hand, since energy requirements change over the season, it should not be optimal to forage with a constant intensity. Behavioural decisions are based on the values of 5 state variables.

(1) Quality of feathers, F: varies between 0 and 1 (in steps of 0.1 ), where 0 is a feather of very poor quality (worn) and 1 is a newly moulted feather. During each time step (week), the rate of abrasion is assumed to be proportional to the amount of energy spent during that week. (2) Energy reserves, $r$ : can vary between 0 (no reserves) and 1 (maximum storage capacity). The reserves are affected by factors such as family status, foraging intensity, migration, etc. (3) Location, l: there are 4 different locations available to the bird: a northern hemisphere breeding site, a temperate stopover site (Stopover 1), an equatorial stopover site, and a southern hemisphere wintering site. Migration at any single time step can only be between nearby sites. In order to realistically describe reproduction, birds are also characterized by (4) experience and (5) family status to take account of juveniles and parental care, respectively. The action taken (or not taken) at each of 52 time steps affects the bird's future state.

For the present study, we have used a variation of the model outlined in Barta et al. (2008) to explore the possible effects of climate change on the timing of migration, breeding and moult. There are no constraints forced onto the system, with the exception of the sinusoidal variation of resources that implement a seasonal environment. In the present model, we have changed the description of food availability to accommodate climate change as follows. The amount of food available at each week, $w$, over the year is given by

$$
A_{\text {food }}+\varepsilon_{\mathrm{F}} \sin \left(t_{p}-R \cos t_{p}\right)
$$

where $t_{\mathrm{p}}=\pi(w-13) / 26 . R$ is a parameter that controls the shape of the resource curve and is used to model effects of climate change on resource phenology. By changing $R$ we can modify the temporal distribution of food, particularly by decreasing $R$ from 0 (the baseline case, reported in Barta et al. 2008) to -1 the length of the favourable season can be increased (i.e. the spring starts earlier and the autumn ends later). This is illustrated by the arrows in Fig. 3. This is our hypothesized effect on food availability due to climate warming at a breeding site at northern latitudes. One may assume other effects as well, but with meteorological definitions of summer being based on mean temperatures, we assume the pattern of Fig. 3 as a first approximation. For $R=-1$ the spring starts $6.1 \mathrm{wk}$ earlier and the autumn ends $6.1 \mathrm{wk}$ later than for the baseline case. In order to investigate the effect of earlier spring we changed $R$ from 0 to -1 on the breeding site and on the stopover site closest to the breeding ground. This and the distribution of food are illustrated in Figs. $4 \& 5$. We allow a new strategy to evolve for the changed conditions, rather than following the performance of the old strategy in a new context.

We create 2 moult scenarios, summer and winter moult, by taking 2 sets of parameters that generate summer and winter moult, respectively (Figs. 4 \& 5).

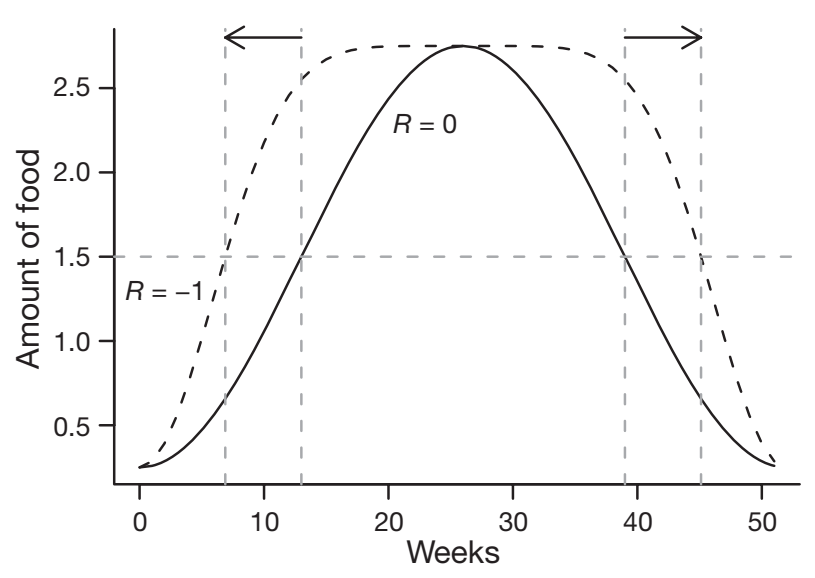

Fig. 3. The hypothetical resource curve at the breeding site and Stopover Site 1 used in the annual routine model. The baseline case is with $R=0$ (solid curve), while an advancement of spring (and postponement of autumn) is modelled as indicated by the broken curve and $R=-1$ 

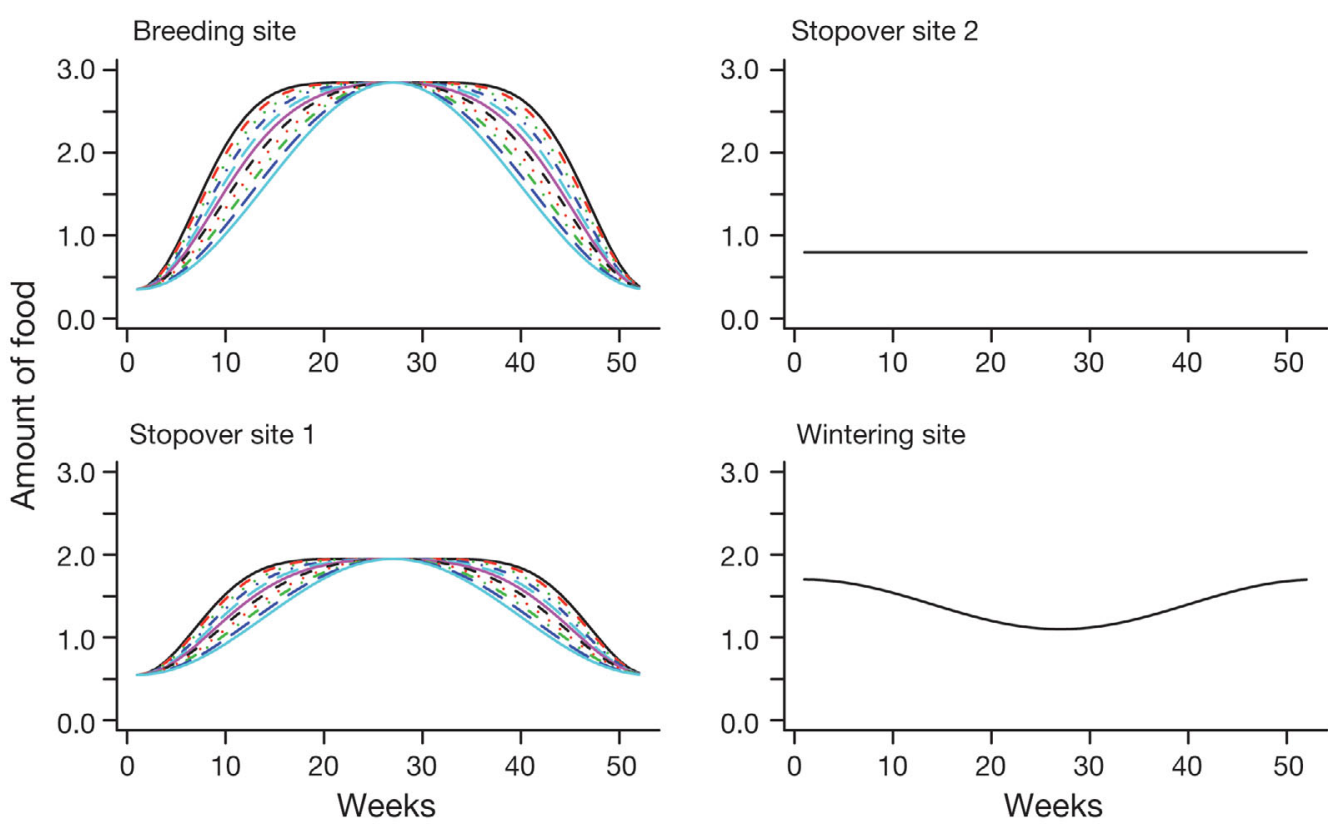

Fig. 4. Hypothetical resource curves at the 4 sites included in the annual routine model for the summer moult scenario. Effects due to climate change were modelled at the breeding site and Stopover Site 1, respectively
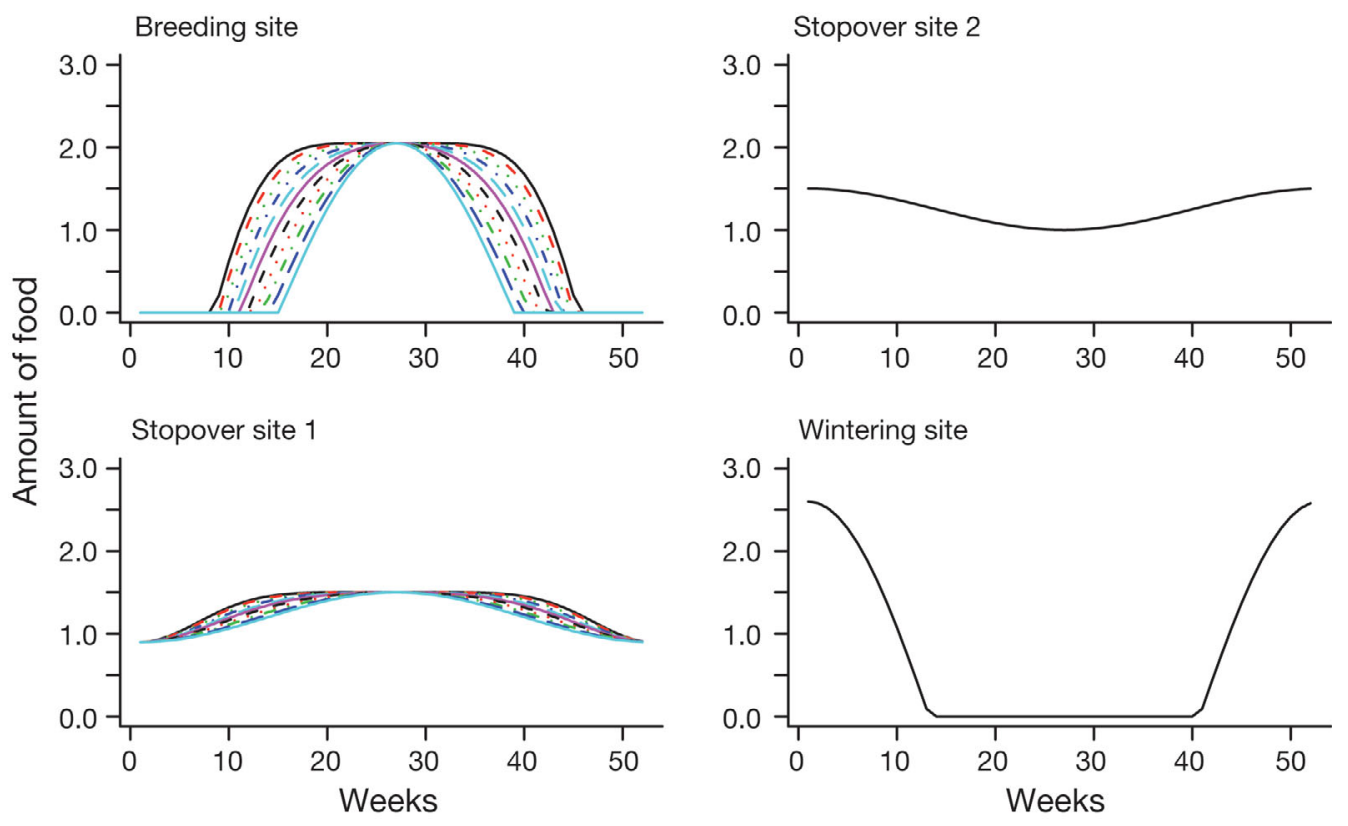

Fig. 5. Hypothetical resource curves at the 4 sites included in the annual routine model for the winter moult scenario. The resource curves at Stopover Site 2 and the wintering site differ from those of the summer moult scenario. Effects due to climate change were models at the breeding site and Stopover Site 1, respectively

These 2 parameter sets are treated as our baseline for change (Barta et al. 2008). In order to generate summer and winter moult scenarios, the resource curves at the equatorial site and the wintering sites are as shown in Figs. 4 \& 5, respectively. In the following, results are portrayed for summer and winter moult conditions in parallel. An interesting point is whether predictions differ between species with summer and winter moult; this difference can, in principle, be tested by comparing recent trends among migratory species having either summer or winter moult.

\subsubsection{Timing of migration}

For summer moult, a 6 wk spring advancement that only affects the breeding site will result in departure from the wintering site being approximately $1 \mathrm{wk}$ earlier (Fig. 6A, open circles), while, if also combined with an advancement at Stopover Site 1, departure is advanced by a further 2 wk. Effects of advanced spring at the stopover site do not depend on how advanced spring is on the breeding grounds. The effects of advancement at the 2 sites are additive. In the winter 
moult scenario, the departure on spring migration from the wintering site is largely unaffected by advancement of spring at either the breeding site or Stopover Site 1 , until the advancement is $>6 \mathrm{wk}$ at the breeding site (Fig. 6B). Advancement at Stopover Site 1 has a negligible effect on the timing of departure from the wintering area. The reason is that the birds have to finish moult at the wintering site before they can take advantage of the improved conditions along the migration route. As the food is not changed at the wintering site in the model, the termination of moult does not change nor does the time of departure on spring migration.

In the summer moult scenario, in contrast to the time of departure from the wintering site, the time of arrival at the breeding area in spring is affected by advancement of the climate change. The advancement of spring at the breeding site alone has a rather small effect (Fig. 7A, open circles). However, if paired with considerably earlier resource availability at Stopover Site 1, the advancement in arrival time matches the advancement of departure from winter grounds (Fig. 7A). For winter moult, only advancement of spring at the breeding site will influence the arrival time, where arrival time is almost parallel to spring advancement (Fig. 7B).

The departure for autumn migration from the breeding site is hardly affected by climate change, with a tendency for postponement only if there is considerable advancement of spring at Stopover Site 1 as well as at the breeding site (Fig. 8A). The pattern is, however, not clear cut; a postponement of autumn migration appears to depend on the magnitude of spring advancement at Stopover Site 1 as well as the breeding grounds. For the winter moult scenario, the departure time on autumn migration remains nearly constant in relation to climate change (Fig. 8B).

\subsubsection{Timing of breeding}

There is a clear response in the timing of the onset of breeding for the summer moult scenario, whereby a $6 \mathrm{wk}$ spring advancement yields approximately a $4 \mathrm{wk}$ shift of the start of breeding (Fig. 9A). Advancement at Stopover Site 1 has little effect unless advancement at the breeding site is $>4 \mathrm{wk}$ (Fig. 9A). For winter moult conditions, the shift of breeding onset is similar to the summer moult case, but the effects at Stopover Site 1 have a negligible impact (Fig. 9B). It appears, for the summer moult scenario, that breeding advances more than arrival, and, therefore, the interval between arrival and onset of breeding is reduced under climate change (Figs. 7A \& 9A). However, for winter moult, the
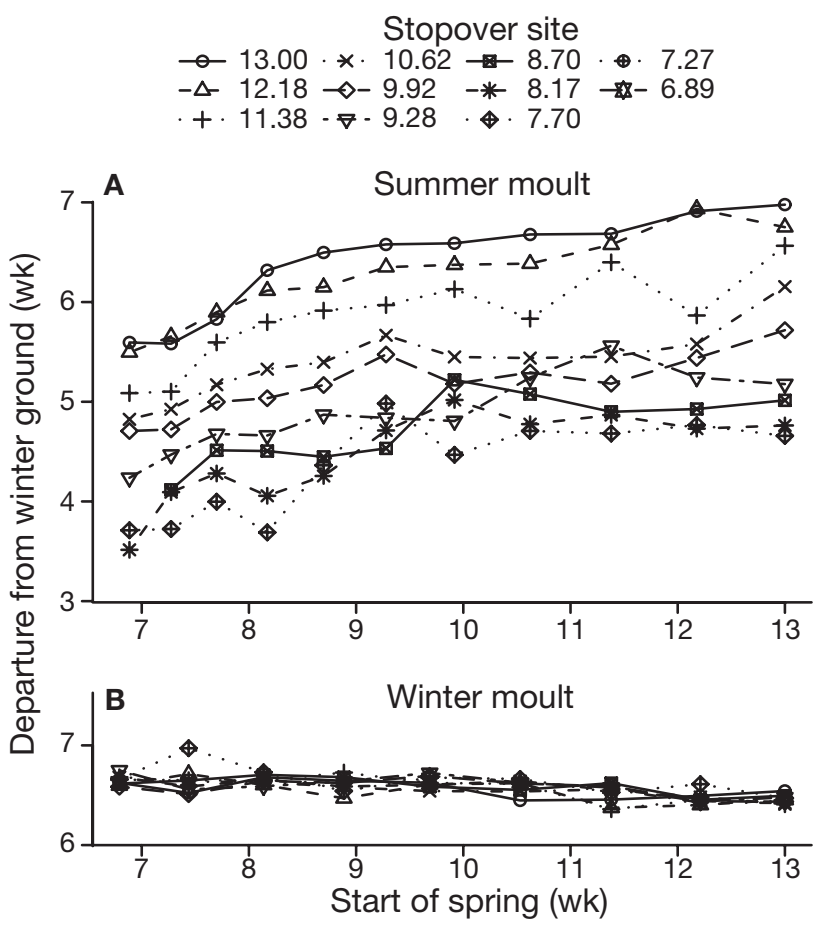

Fig. 6. Departure time from the wintering site in relation to advancement of spring at the breeding site $(R=0.1)$. The curves represent effects at Stopover Site 1, with numbers indicating $t_{\mathrm{p}}$, which is advancement in weeks: (A) summer moult and (B) winter moult

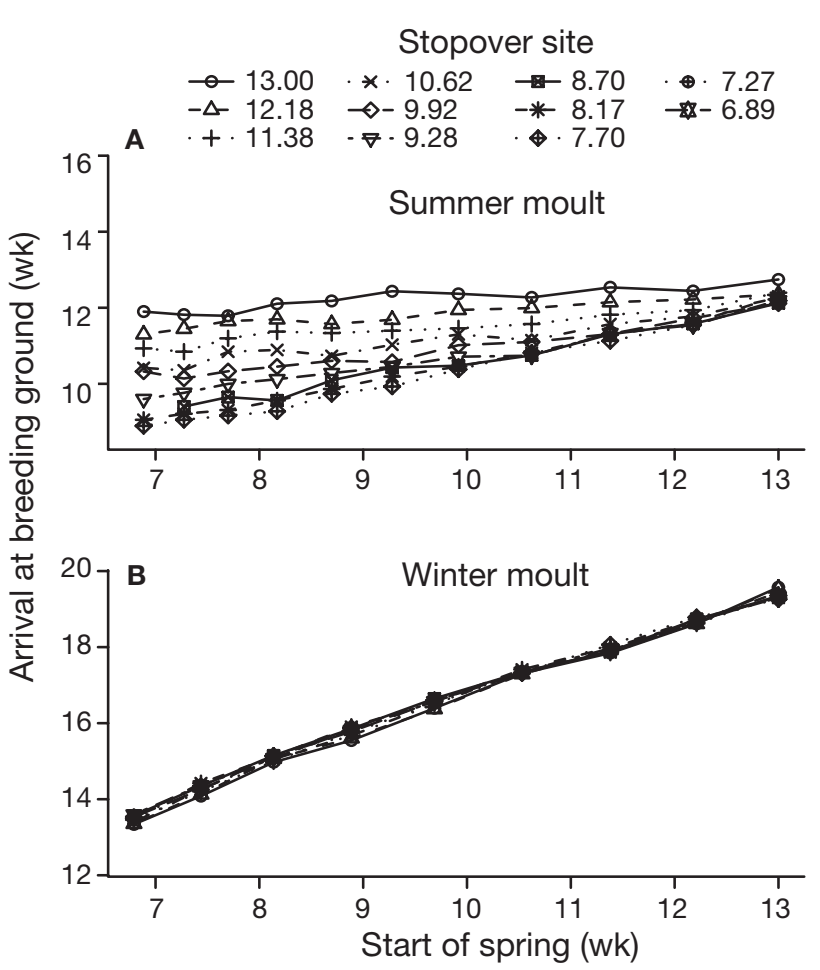

Fig. 7. Arrival time at the breeding site in relation to advancement of spring at the breeding site $(R=0.1)$. The curves represent effects at Stopover Site 1, with numbers indicating $t_{\mathrm{p}}$ which is advancement in weeks: (A) summer moult and (B) winter moult 


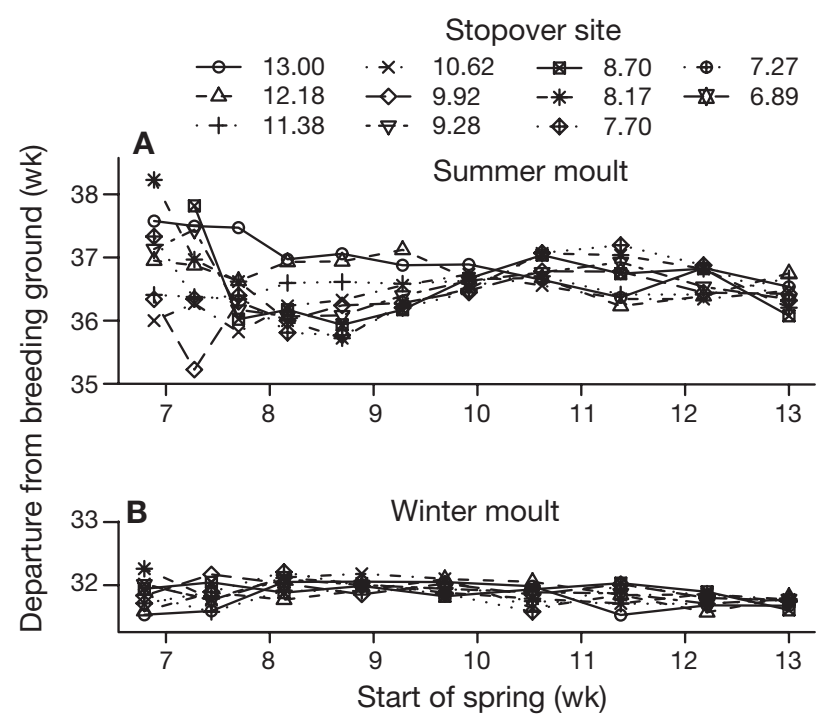

Fig. 8. Departure from the breeding site (autumn migration) in relation to advancement of spring at the breeding site $(R=$ $0.1)$. The curves represent effects at Stopover Site 1, with numbers indicating $t_{\mathrm{p}}$, which is advancement in weeks: (A) summer moult and (B) winter moult

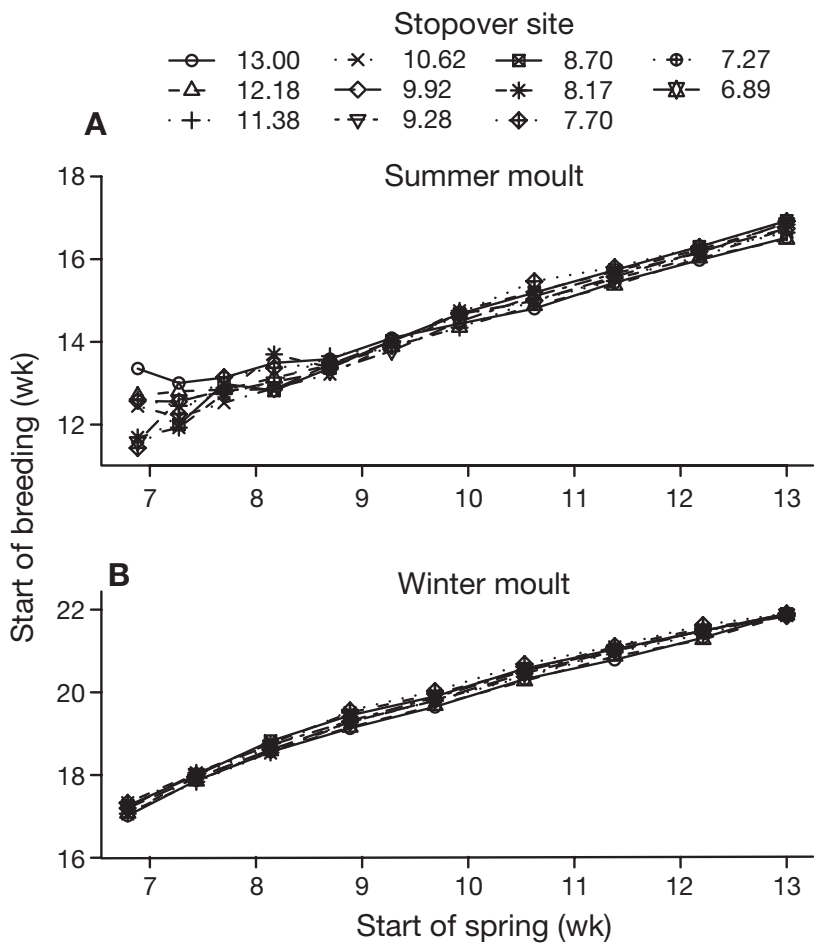

Fig. 9. Start of breeding in relation to advancement of spring at the breeding site $(R=0.1)$. The curves represent effects at Stopover Site 1, with numbers indicating $t_{\mathrm{p}}$, which is advancement in weeks: (A) summer moult and (B) winter moult

shifts of arrival and breeding time are parallel, and, hence, the pre-breeding interval is largely unaffected (Figs. 7B \& 9B).

\subsubsection{Number of breeding attempts}

The birds of this model are allowed to breed repeatedly during 1 breeding season. This can be assessed as the number of breeding attempts or the number of successful breeding attempts. Both measures show similar effects, and, therefore, only results for the number of successful breeding attempts are shown. Both moult scenarios considered show an increase of successful breeding attempts with advancement of spring (and hence extension of the breeding season), while an advancement at Stopover Site 1 had small and variable effects (Fig. 10). However, since the population is at a density-dependent equilibrium (Barta et al. 2008), these changes are accompanied by an increased mortality rate.

\subsubsection{Timing of moult}

It comes as a surprise that the timing of moult is unaffected by the advancement of spring at both the breeding site and Stopover Site 1, because the timing of moult should be rather plastic. This holds for both the summer and winter moult scenarios (Fig. 11). Both the departure date and timing of moult are optimized to survive the winter. For winter moult, birds must fit the costly moult into a relatively short winter. Therefore, they cannot depart later from the breeding ground (even if possible due to longer summer) because this would shorten the time available for moulting at the wintering site. This is shown by the fact that birds in the winter moult scenario do not leave earlier from the wintering site as they need the whole winter to complete moult. As we do not change the conditions at the wintering site, birds do not change their departure date or timing of moult. For the summer moult scenario, birds leave the wintering site earlier if spring advances at the breeding grounds (see Section 2.2.2), but they need time for accumulating fuel before departing. If they leave the breeding site later because of a longer summer season, they would have less time to improve their fuel load at the wintering site. So, why not leave the breeding site earlier to increase the available time at the wintering site? This would imply that available resources are too low upon arrival at the wintering site, and, therefore, birds leave the breeding grounds as early as they possibly can.

\section{DISCUSSION}

There are many papers reporting on changed spring arrival of migratory birds, an effect which is usually attributed to recent climate change (Lehikoinen et al. 2004, Jonzen et al. 2006, Rubolini et al. 2007, this issue). Fewer studies report on other avian life-history 


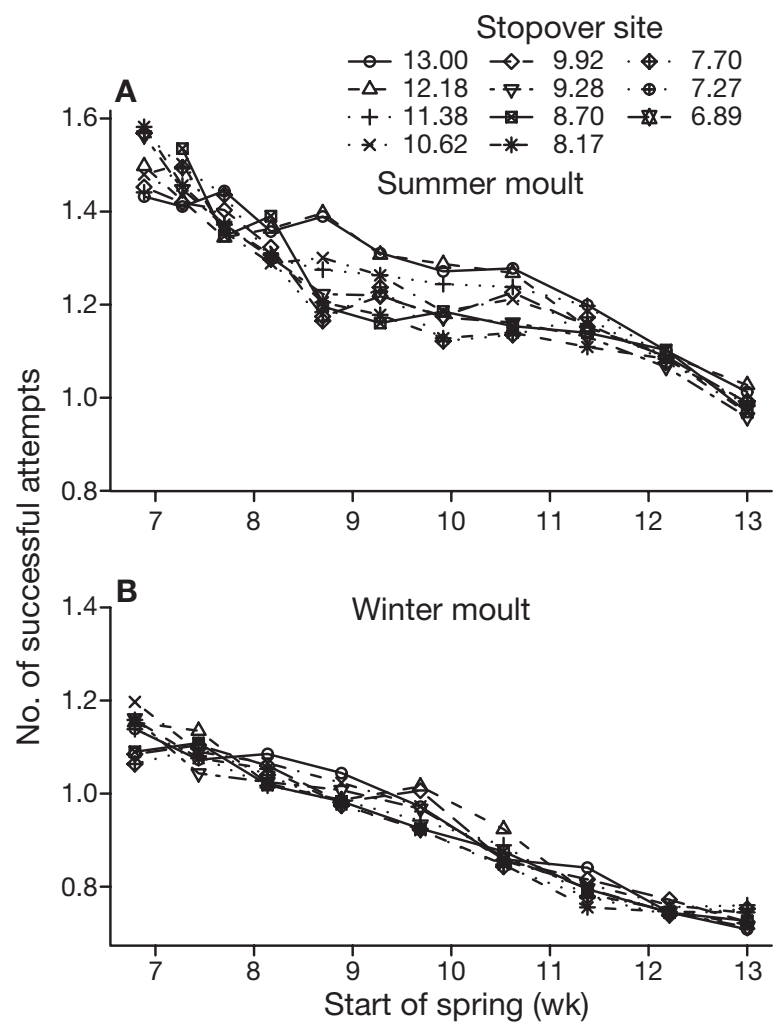

Fig. 10. Number of successful broods in relation to advancement of spring at the breeding site $(R=0.1)$. The curves represent effects at Stopover Site 1, with numbers indicating $t_{\mathrm{p}}$ which is advancement in weeks: (A) summer moult and (B) winter moult

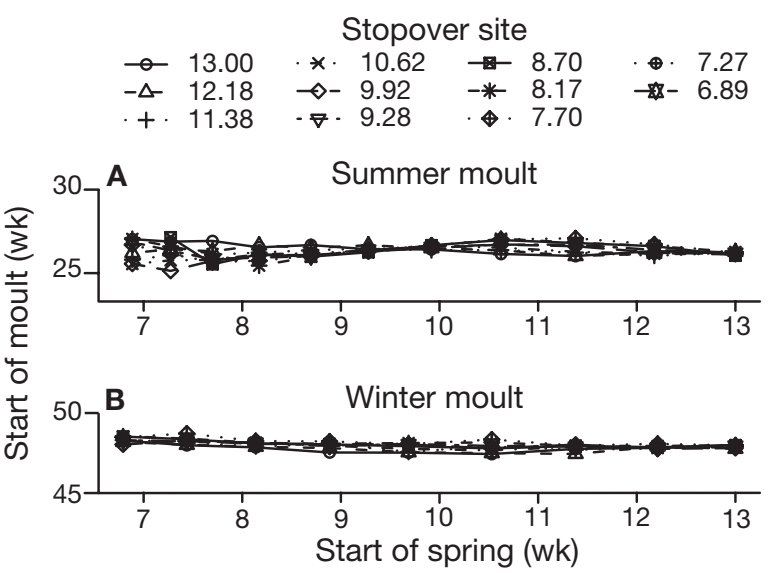

Fig. 11. Start of moult in relation to advancement of spring at the breeding site $(R=0.1)$. The curves represent effects at Stopover Site 1, with numbers indicating $t_{\mathrm{p}}$, which is advancement in weeks: (A) summer moult and (B) winter moult

parameters that are also being affected by climate change, although they are equally likely to arise. Other observations include changes in autumn migration (Cotton 2003, Jenni \& Kéry 2003) and in timing of breeding in relation to migration as a possible result of differential responses to migration and onset of breeding. In some pied flycatcher Ficedula hypoleuca populations there is a reduced time between arrival and onset of breeding, which has been interpreted as indication of a 'mismatch' due to a too late arrival in relation to a shift in the food peak (Both \& Visser 2001). Depending on trade-offs between fitness components, such as adult survival and reproductive success, Jonzén et al. (2007) showed that changed time between arrival and breeding onset could also be interpreted as an adaptive response to a new regime.

In the first part of our paper, we modelled effects of climate change on overall migration speed. We analyzed the factors most likely to affect the migration speed, assuming increased food availability along the flyway. If migration speed is below the physiologically possible maximum speed, mainly set by the capacity to accumulate fuel, there is a scope for increasing the migration speed up to the limit where the physiological constraint prevents further increases. Some birds are likely to already operate close to the maximum migration speed (some shorebirds, geese and swans), and in these cases we do not expect any increased rates. In many small passerines there is probably room for increased migration speed, and increased spring migration speed has in fact been observed in North America (Marra et al. 2005) and Europe (Both et al. 2005).

In certain goose and shorebird species spring migration is very rapid and occurs at a relatively late date, since their arctic breeding sites become available later with a short spring. Some of these birds follow a 'green wave' on spring migration, and successful migration depends on the timing of this wave (Owen 1980, van der Graaf et al. 2006). If the food peak at a particular stopover site is shifted, the result may be that this stopover site is abandoned by a population. When migration depends on the quality of individual sites like this, perturbations due to climate change may be very critical for the migration of the birds (Drent et al. 2006). Some of these arctic birds also bring some resources for breeding from stopover sites into the breeding site, a strategy termed 'capital breeding' (as opposed to 'income breeding', when all resources for breeding are obtained at the breeding site). This depends on the relative fuelling rate between the final stopover site and the breeding site (Alerstam 2006, Hedenström 2006). This behaviour is also likely to be affected if climate change modifies the relative fuelling capacity among stopover sites and the breeding site.

The second part of our paper addressed annualcycle consequences of changes in the time course of food availability under climate change. Our model implemented a scenario of a progressively earlier rise and later decline in food availability. It should, however, be kept in mind that effects of climate change 
may take other forms, such as affecting one season more than the other, shifting the timing of maximal food supply (e.g. Both et al. 2006), or changing the amplitude of the resource curves. We provide a number of expected outcomes regarding timing of migration, onset of breeding, number of breeding attempts and moult. An earlier and longer availability of resources under climate change generally advanced the timing of spring migration (departure from winter grounds and arrival on breeding grounds). Breeding started earlier, and birds were able to raise more clutches. In contrast, the timing of moult and of fall migration (departure from the breeding grounds) were largely unaffected. Changes in the timing of spring migration depended on the advancement of spring at the last stopover site, in addition to its advancement at the breeding grounds. Thus, there are clearly different expected responses depending on whether climate change affects the breeding site and/or the nearest stopover site. Hence, depending on how 'global' the ecological effects of climate change are, we may have different expected outcomes. There are also differing outcomes depending on whether birds moult in the breeding or wintering area. These effects should be testable by comparing species of these 2 moult categories. Inspection of data for a few species with summer and winter moult did not reveal any obvious differences in the change of migration timing (see Jonzén et al. 2006), but this data set is certainly not sufficient for a critical test of this hypothesis.

Furthermore, there are grounds for expecting deviations from these predictions that relate to the particular biology of species. For instance, a general observation is that large birds are expected to have less 'surplus' time when breeding, migration and moult have been completed (Hedenström 2006). Hence, a corollary from this is that large birds are more time-constrained than small birds, and, hence, only relatively small modifications of their annual cycle can be expected. Another relevant question is how locked into different annual schedules birds are, and how flexible individual traits can be. As explained above, the model predicts optimal seasonal strategies without regard for the diverse mechanisms allowing their implementation. Assuming that the proposed model accurately predicts ecologically optimal solutions for annual routines under global change, their actual implementation may thus be affected by the physiological and genetic organization of a species' seasonal cycle. The model is based on the assumption that birds have an accurate calendar by which they anticipate the correct time for a given behaviour, e.g. departure from remote winter grounds. Field and captivity data provide good evidence for high-precision time-keeping and individual consistency at least in some species (Gwinner 1996, Pulido \&
Berthold 2003, Battley 2006, Van Noordwijk et al. 2006). Many long-distance migrants rely on timing programs that consist of an internal (circannual) clock and its adjustment by environmental information, especially day length (Gwinner 1996, Hall \& Fransson 2000, Gwinner \& Helm 2003, Coppack \& Pulido 2004). To remain accurate, this clock is partly buffered from environmental noise (e.g. unusual or novel weather conditions), and possesses mechanisms that bring birds 'back on track' if they behave out of season. For example, wide-spread 'calendar effects' ensure timely moult and autumn departure by accelerating seasonal behaviour late in the season (Jenni \& Winkler 1994, Hall \& Fransson 2000, Helm et al. 2005). Conversely, early in the season reproduction is often only possible once a critical day length threshold is exceeded (Silverin et al. 1993, Lambrechts et al. 1996). Experimental manipulations involving shifts in the day:night light regime provide potent ways of studying these mechanisms.

The mechanistic basis of seasonal behaviour has several possible implications for the implementation of optimal annual routines. First, timing programs may result in inertia or offset effects of changed seasonal timing. When stonechats Saxicola torquata were offered conducive breeding conditions in aviary experiments, their use of this opportunity differed between populations. While African residents and European short-distance migrants bred over long intervals, longdistance migrant Siberian stonechats retained the short breeding schedule of their native grounds (Helm et al. 2005). Such limited flexibility accords with other findings of particularly rigid timing programs in longdistance migrants (Jenni \& Winkler 1994, Gwinner 1996). When temporal flexibility occurs, modified schedules can be readjusted by timing programs. Young stonechats in the field and laboratory developed and moulted progressively faster with later date of hatching. For every day they hatched later in the season, migratory activity of captive young started $0.9 \mathrm{~d}$ earlier in life. Thus, due to photoperiodic programs, these birds compensated for $90 \%$ of the time difference in parental reproduction (Flinks 1999, Helm et al. 2005). Second, timing programs may lead to phase-shifts of annual routines. Captive stonechats that experienced breeding day length slightly later in spring, as part of simulated later arrival, delayed the termination of breeding and the onset of moult accordingly (Helm \& Gwinner 2005). Genetic correlations between the timing of different seasonal behaviours may have similar effects, e.g. by coupling early termination of moult to early departure (Van Noordwijk et al. 2006). These mechanisms could explain the observed early departure of some migrants with advanced arrival schedules (Cotton 2003, Jenni \& Kéry 2003). Third, changes in seasonal schedules may lead to additional time shifts 
along trajectories set by timing programs. For example, increasing day length in spring stimulates breeding condition in birds. Migration to higher latitudes, thus, enhances the readiness to breed because in spring and summer day length increases with latitude. However, with progressively earlier departure from the winter grounds, birds may migrate before the spring equinox (ca. 21 March) and encounter the reverse, i.e. shorter day length, as they move to higher latitudes. These trajectories can also provide the mechanistic basis for 'phase jumps' of seasonal behaviours, for instance the transition between summer and winter moult that had marked effects in the proposed model, or transitions from being single-brooded to being multiple-brooded. Such transitions are commonly observed in closely related taxa and are apparently relatively easy to achieve (e.g. Jenni \& Winkler 1994, Helm et al. 2005, Helm 2006).

Effects of the mechanistic organization on annual routines under climate change can therefore be diverse. Comparative studies of populations provide strong evidence for distinct, presumably adaptive, geographic differentiation of timing programs (Silverin et al. 1993, Lambrechts et al. 1996, Helm et al. 2005). In addition, schedules are also determined by other factors, for instance direct responses to local weather (Cochran \& Wikelski 2005, Nilsson et al. 2006, Gienapp et al. 2008). Thus, in species with considerable behavioural plasticity, schedules may be more readily modified and approximate predicted optimal annual routines. In view of rapid global change, it remains to be seen if change will occur fast enough for optimal adjustment to novel conditions. In some species, slow change has been associated with considerable population declines (Both et al. 2006). In others, change has been rapid and unexpectedly reinforced, e.g., by nonrandom mating (Bearhop et al. 2005). Provided that species adjust sufficiently fast, their annual routines may assume optima that could be predicted from the suggested model and consideration of their particular behavioural, physiological and genetic organization.

Acknowledgements. We are grateful for the comments made by two anonymous referees. This work was supported by a grant from the Swedish Research Council. A.H. is a Royal Swedish Academy of Sciences Research Fellow supported by a grant from the Knut and Alice Wallenberg Foundation. Z.B. was supported by a BBSRC grant (to A.I.H and J.M.McN), and by OTKA grants (NF 61143, T046661).

\section{LITERATURE CITED}

Ahola M, Laaksonen T, Sippola $K$, Eeva T, Rainio K, Lehokoinen E (2004) Variation in climate warming along the migration route uncouples arrival and breeding dates. Glob Change Biol 10:1610-1617
Alerstam T (1991) Bird flight and optimal migration. Trends Ecol Evol 6:210-215

Alerstam T (2006) Strategies for the transition to breeding in time-selected bird migration. Ardea 94:347-357

Alerstam T, Hedenström A (1998) The development of bird migration theory. J Avian Biol 29:343-369

Askew GN, Ellerby DJ (2007) The mechanical power requirements of avian flight. Biol Lett 3:445-448. doi:10.1098/ rsbl.2007.0182

Barta Z, Houston AI, McNamara J, Welham RK, Hedenström A, Weber TP, Feró O (2006) Annual routines of non-migratory birds: optimal moult strategies. Oikos 112:580-593

Barta Z, McNamara JM, Houston AI, Weber TP, Hedenström A, Feró O (2008) Optimal moult strategies in migratory birds. Philos Trans R Soc B 363:211-229

Battley PF (2006) Consistent annual schedules in a migratory shorebird. Biol Lett 2:517-520

Bearhop S, Fiedler W, Furness RW, Votier SC and others (2005) Assortative mating as a mechanism for rapid evolution of a migratory divide. Science 310:502-504

Both C, Visser ME (2001) Adjustment to climate change is constrained by arrival date in a long-distance migrant bird. Nature 411:296-298

Both C, Bijlsma RG, Visser ME (2005) Climate effects on timing of spring migration and breeding in a long-distance migrant, the pied flycatcher Ficedula hypoleuca. J Avian Biol 36:368-373

Both C, Bouwhuis S, Lessells CM, Visser ME (2006) Climate change and population declines in a long-distance migratory bird. Nature 441:81-83

Clark CW, Mangel M (2000) Dynamic state variable models in ecology. Oxford University Press, New York

Cochran W, Wikelski M (2005) Individual migratory tactics of New World Catharus thrushes: current knowledge and future tracking options from space. In: Greenberg $R$, Marra P (eds) Birds of two worlds. Johns Hopkins University Press, Baltimore, p 274-289

Coppack T, Pulido F (2004) Photoperiodic response and the adaptability of avian life cycles to environmental change. Adv Ecol Res 35:131-150

Cotton PA (2003) Avian migration phenology and global climate change. Proc Natl Acad Sci USA 100:12219-12222

Crick HMP, Dudley C, Glue DE, Thomson DL (1997) UK birds are laying eggs earlier. Nature 388:526

Drent RH, Fox AD, Stahl J (2006) Travelling to breed. J Ornithol 147:122-134

Dunn P (2004) Breeding dates and reproductive performance. Adv Ecol Res 35:69-87

Flinks H (1999) Muster, Intensität und zeitliche Aspekte der postjuvenilen Mauser beim Schwarzkehlchen (Saxicola torquata). Vogelwarte 40:11-27

Gienapp P, Teplitzky C, Alho JS, Mills A, Merilä J (2008) Climate change and evolution: disentangling environmental and genetic responses. Mol Ecol 17:167-178, doi:10.111/ j.1365-294X.2007.03413.x

Graham JB, Dudley R, Aguilar NM, Gans C (1995) Implications of the late Palaeozoic oxygen pulse for physiology and evolution. Nature 375:117-120

Gwinner E (1996) Circannual clocks in avian reproduction and migration. Ibis 138:47-63

Gwinner E, Helm B (2003) Circannual and circadian contributions to the timing of avian migration. In: Berthold P, Gwinner E, Sonnenschein E (eds) Avian migration. Springer-Verlag, Heidelberg, p 81-95

Hall KS, Fransson T (2000) Lesser whitethroats under timeconstraint moult more rapidly and grow shorter feathers. J Avian Biol 31:583-587 
Hedenström A (2003) Scaling migration speed in animals that run, swim and fly. J Zool 259:155-160

Hedenström A (2006) Scaling of migration and the annual cycle of birds. Ardea 94:399-408

Hedenström A, Alerstam T (1995) Optimal flight speed of birds. Philos Trans R Soc Lond B 348:471-487

Hedenström A, Alerstam T (1997) Optimum fuel loads in migratory birds: distinguishing between time and energy minimization. J Theor Biol 189:227-234

Hedenström A, Alerstam T (1998) How fast can birds migrate? J Avian Biol 189:227-234

Helm B (2006) Point of view: zugunruhe of migratory and non-migratory birds in a circannual context. J Avian Biol 37:533-540

Helm B, Gwinner E (2005) Carry-over effects of day length during spring migration. J Ornithol 146:348-354

Helm B, Gwinner E, Trost L (2005) Flexible seasonal timing and migratory behavior: results from stonechat breeding programs. Ann N Y Acad Sci 1046:216-227

Houston AI (1998) Models of optimal avian migration: state, time and predation. J Avian Biol 29:395-404

Houston AI (2000) The strength of selection in the context of migration speed. Proc R Soc Lond B Biol Sci 267: 2393-2395

Houston AI, McNamara JM (1999) Models of adaptive behaviour. Cambridge University Press

Houston AI, McNamara JM, Clark CW, Mangel M (1988) Dynamic models in behavioural and evolutionary ecology. Nature 332:29-34

Hüppop O, Hüppop K (2003) North Atlantic Oscillation and timing of spring migration in birds. Proc R Soc Lond B 270: 233-240

IPCC (Intergovernmental Panel on Climate Change) (2001) Contribution of Working Group II to the Third Assessment Report of the Intergovernmental Panel on Climate Change. Cambridge University Press

Jenni L, Kéry M (2003) Timing of autumn bird migration under climate change: advances in long-distance migrants, delays in short-distance migrants. Proc R Soc Lond B 270: $1467-1471$

Jenni L, Winkler R (1994) Moult and ageing of European passerines. Academic Press, London

Jonzén N, Lindén A, Ergon T, Knudsen E and others (2006) Rapid advance of spring arrival dates in long-distance migratory birds. Science 312:1959-1961

Jonzén N, Hedenström A, Lundberg P (2007) Climate change and the optimal arrival of migratory birds. Proc R Soc Lond B 274:269-274

Kirkwood JK (1983) A limit to metabolisable energy intake in mammals and birds. Comp Biochem Physiol A 75:1-3

Lambrechts MM, Perret P, Blondel J (1996) Adaptive differences in the timing of egg laying between different populations of birds result from variation in photoresponsiveness. Proc R Soc Lond B 263:19-22

Lehikoinen E, Sparks TH, Zalakevicius M (2004) Arrival and departure dates. Adv Ecol Res 35:1-31

Lindström $\AA$ (1991) Maximum fat deposition rates in migrating birds. Ornis Scand 22:12-19

Marra PP, Francis CM, Mulvihill RS, Moore FR (2005) The influence of climate on the timing and rate of spring bird migration. Oecologia 142:307-315

McNamara JM, Houston AI (2008) Optimal annual routines: behaviour in the context of physiology and ecology. Philos Trans R Soc Lond B 363:301-319, doi:10.1098/ rstb.2007.2141

McNamara JM, Welham RK, Houston AI (1998) The timing of migration within the context of an annual routine. J Avian Biol 29:416-423

Nilsson A, Alerstam T, Nilsson JA (2006) Do partial and regular migrants differ in their responses to weather? Auk 123:537-547

Norris DR, Marra P, Kyser T, Sherry T, Ratcliffe L (2004a) Tropical winter habitat limits reproductive success on the temperate breeding grounds in a migratory bird. Proc $\mathrm{R}$ Soc Lond B 271:59-64

Norris DR, Marra P, Montgomerie R, Kyser T, Ratcliffe L (2004b) Reproductive effort, molting latitude, and feather color in a migratory songbird. Science 306:2249-2250

Owen M (1980) Wild geese of the world. Batsford Ltd., London

Pennycuick CP (1975) Mechanics of flight. In: Farner DS, King JR, Parkes KC (eds) Avian biology, Vol. 5. Academic Press, New York, p 1-75

Pennycuick CJ (1989) Bird flight performce: a practical calculation manual. Oxford University Press

Pulido F, Berthold P (2003) Quantitative genetic analyses of migratory behaviour. In: Berthold P, Gwinner E, Sonnenschein E (eds) Avian migration. Springer-Verlag, Heidelberg, p 53-77

Rubolini D, Møller AP, Rainio K, Lehikoinen E (2007) Intraspecific consistency and geographic variability in temporal trends of spring migration phenology among European bird species. Clim Res 35:135-146

Silverin B, Massa R, Stokkan K (1993) Photoperiodic adaptation to breeding at different latitudes in great tits. Gen Comp Endocrinol 90:14-22

Stervander M, Lindström Å, Jonzén N, Andersson A (2005) Timing of spring migration in birds: long-term trends, North Atlantic Oscillation and the significance of different migration routes. J Avian Biol 36:210-221

Tobalske BW, Hedrick TL, Dial KP, Biewener AA (2003) Comparative power curves in bird flight. Nature 421:363-366

Tøttrup AP, Thorup K, Rahbeck C (2006) Patterns of change in timing of spring migration in North European songbird populations. J Avian Biol 37:84-92

van der Graaf AJ, Stahl J, Klimkowska A, Bakker JP, Drent RH (2006) Surfing on a green wave-how plant growth drives spring migration in the barnacle goose Branta leucopsis. Ardea 94:567-577

Van Noordwijk AJ (2003) Climate change: the earlier bird. Nature 422:29

Van Noordwijk A, Pulido F, Helm B, Coppack T and others (2006) A framework for the study of genetic variation in migratory behavior. J Ornithol 147:221-234

Weber TP, Houston AI, Ens BJ (1994) Optimal departure fat loads and site use in avian migration: an analytical model. Proc R Soc Lond B 258:29-34

Webster MS, Marra PP, Haig SM, Bensch S, Holmes RT (2002) Links between worlds: unraveling migratory connectivity. Trends Ecol Evol 17:76-83 
Appendix 1. Fixed versus optimal flight speed. For definitions of $E_{0}-C_{0}, P$, see Eq. (1) in main text

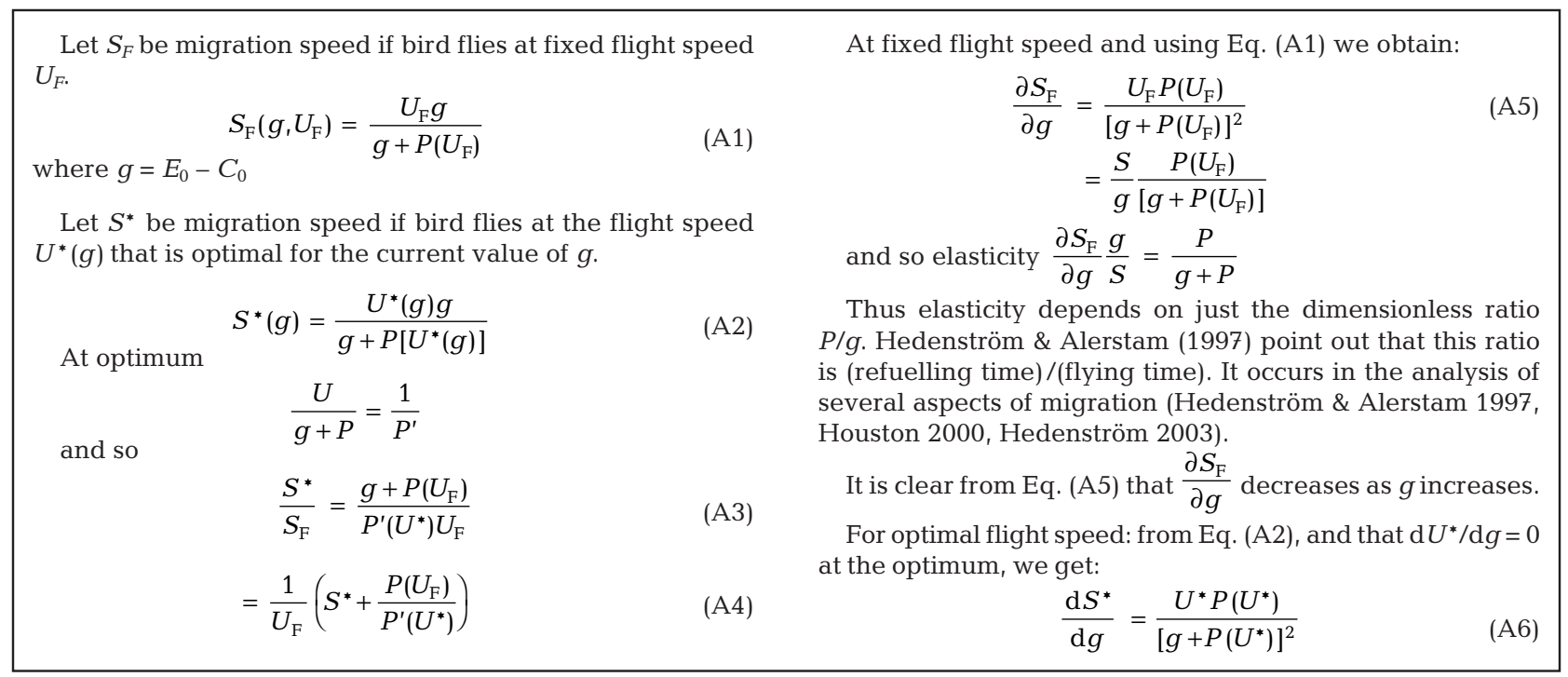

